Copyright: ( 2014 IEEE. Personal use of this material is permitted. Permission from IEEE must be obtained for all other uses, in any current or future media, including reprinting/republishing this material for advertising or promotional purposes, creating new collective works, for resale or redistribution to servers or lists, or reuse of any copyrighted component of this work in other works.

This is the Author's Accepted Manuscript version, uploaded in accordance with the publisher's selfarchiving policy. The definitive version is available at: http://dx.doi.org/10.1109/SOLI.2014.6960702.

Suggested Citation: Zhou, Zhenkun, Lin, Yong and Yue, Feng (2014) Service-dominant logic for exploring modular business service system. In: 2014 IEEE International Conference on Service Operations and Logistics, and Informatics (SOLI). Institute of Electrical and Electronics Engineers, Inc., Piscataway, NJ, USA, pp. 108-112. ISBN 9781479960583 (doi:10.1109/SOLI.2014.6960702) 


\section{Service-Dominant Logic for Exploring Modular Business Service System}

\author{
Zhenkun Zhou \\ Shenzhen Institute of Information \\ Technology \\ Shenzhen, Guangdong Province, \\ China \\ zhouzk77@gmail.com
}

\author{
Yong Lin \\ University of Greenwich \\ London, UK \\ yonglin1212@gmail.com
}

\author{
Feng Yue \\ Chanjet Information Technology \\ Co., LTD \\ Beijing, China \\ yf@chanjet.com.cn
}

\begin{abstract}
-investigating the management of the three dimensions of modular business service system from the perspective of the service-dominant (S-D) logic. An integrated approach with an abductive research process in theory building was conducted through case study. The results show that ten foundational premises of S-D logic, especially service -focused, customeroriented, and rational views can be applied in defining and managing the modular business service system constructed by service modularization.
\end{abstract}

Keywords- service-dominant logic; service modularity; process modularity; organization modularity; value co-creation;case study

\section{INTRODUCTION}

The global economy is a large service system in need of innovation to grow [1], and such complex service systems are "value co-creation configurations of people, technology, value propositions connecting internal and external service systems and shared information [2]". Therefore, the normative function of this service system is to connect people, technology and information through value propositions with the aim of cocreating value for all service systems participating in the exchange of resources. The challenge with developing their function is so difficult to make trade-offs logically among the twelve dimensions of complexity features [3]. Although service-dominant(S-D) logic [4] might provide just the right perspective, vocabulary, and assumptions on which to build a theoretical framework for the study of service systems [2], however, exploring an S-D-logic-grounded service system is continuing [5].

This study aims to explore an S-D-logic-grounded service system from a service modularization perspective, and to propose its implications for operations management. Particularly in managing modular business service system, the S-D logic can serve to facilitate the value co-creation during service provision, but its implementation in this field is still scarce in current literature. Notably, according to the work of Weick [6] and Pekkarinen and Ulkuniemi [7], in this paper, a research question is raised:
$R Q 1$ : How to manage modular business service system in terms of service, process and organization from the perspective of the S-D logic?

In the rest of this article, background is presented, which reviews the service-dominant logic and service modularization literature with particular focus on the issues of managing operations. Then, the research question and methodology are presented. Finally, the findings of the field study are outlined and the conclusions are drawn.

\section{BACKGROUND}

\section{A. Service-Dominant Logic ( $S$-D logic)}

The S-D logic is rooted on ten FPs (see Table 1). According to the S-D logic, all economies are service economies (FP5) and service is regarded as the fundamental basis of exchange (FP1), while goods are defined as a distribution mechanism for service provision (FP3), not the basic unit and focus of exchange as found in the G-D logic. However, the serviceexchange-service is not always apparent due to the service is always provided through complex combinations of money, goods, organizations, and vertical marketing systems [4], such complex indirect exchange actually will mask the fundamental basis of the economic exchange (FP2).

Besides that, S-D logic emphasizes that value is always cocreated in a process that requires the active participation of the firm, its customers and other stakeholders [8]. In other words, value is not created until the beneficiary of a service (e.g., customer) integrates and applies the resources of a particular service provider (e.g., firm) with other resources [5], which highlights the customer as the co-creator of value (FP6) as well as that firms cannot create and deliver value; they can only propose value propositions [10] (FP7). Thus, value is always based on the above context and phenomenological perspective, which is always derived and determined by the beneficiary (FP10)

Moreover, this emergent logic reflects the shift from tangible operand resources (e.g. natural resources) in exchange to intangible and dynamic operant resources (e.g. knowledge and skills) for competitive advantage (FP4). More specially, 
Lusch et al., [11] emphasizes the important role of firm in resource integration, and therefore this resource-integration process (FP9) occurs within and among service systems as resources are exchanged to create value for all participating service systems.

TABLE I. FPs of the S-D logic (Adapted from Vargo and Lusch, 2008)

\begin{tabular}{|c|c|}
\hline FPs & Modified/new FPs \\
\hline FP1 & Service is the fundamental basis of exchange \\
\hline FP2 & Indirect exchange masks the fundamental basis of exchange \\
\hline FP3 & Goods are distribution mechanisms for service provision \\
\hline FP4 & $\begin{array}{c}\text { Operant resources are the fundamental source of competitive } \\
\text { advantage }\end{array}$ \\
\hline FP5 & All economies are service economies \\
\hline FP6 & $\begin{array}{c}\text { The customer is always a co-creator of value } \\
\text { propositions }\end{array}$ \\
\hline FP7 & $\begin{array}{c}\text { The enterprise cannot only make value } \\
\text { relational }\end{array}$ \\
\hline FP8 & $\begin{array}{c}\text { A service-centered view is inherently customer oriented and } \\
\text { FP9 }\end{array}$ \\
\hline FP10 & $\begin{array}{c}\text { Vlll social and economic actors are resource integrators } \\
\text { the beneficiary }\end{array}$ \\
\hline
\end{tabular}

\section{B. Loosely coupling and modular service system}

According to Maglio and Spohrer [2], "from S-D logic, we define a service system as a dynamic value co-creation configuration of resources, including people, organization, shared information (language, laws, measures, methods), and technology, all connected internally and externally to other service systems by value propositions." Furthermore, the "venue" of value creation in service systems takes place in the value configurations - interactions among social and economic actors - and thus, value is created within and among service systems, at various levels of aggregation [8]. As such, this value networks are "spontaneously sensing and responding spatial and temporal structure of largely loosely proposing social and economic actors through institutions and technology, to (1) co-produce service offerings, (2) exchange service offerings, and (3) co-create value" [12].

Put differently, a service system is characterized as loose coupling defined by Weick [6], which means a situation in which elements are responsive, but retain evidence of separateness and identity. What is more, this loose coupling system has specific effects in modularity, requisite variety and discretion [13]. Wherein, modularity is crucial. Pekkarinen and Ulkuniemi [7]explored the literature related to modularity and constructed an empirically grounded model for 3D modular service platform including service modularity, process modularity and organization modularity to identify, develop and deliver new business services. As well, this service modularization approach is well applied broadly in various service contexts [14]; [15]; [16].

As described above, business service system in this study is loosely coupling and able to be modularized, as well a complex
S-D-logic-grounded service system can be co-created in a very modular manner by creating a net of service systems including service modularity, process modularity and organization modularity to co-create supporting services.

\section{RESEARCH QUESTION AND METHODOLOGY}

Reviewing the literature on the scope of service modularization and S-D logic, a missing link can be found. The S-D logic with the key FPs of service and value co-creation appears to benefit for design of this modular business service system. However, how to manage this modular business service system composed of service modularity, process modularity and organization modularity applying S-D logic and co-create value between the service provider and service consumers. Therefore, this paper aims to leverage S-D logic to identify the modular business service system covering these three dimensions, and to identify the enablers to coordinate and manage the relationships between them.

Exploring this issue requires an in-depth understanding of the peculiarities of a specific unit of analysis. If this emerging study is to investigate S-D logic in service modularization research fields and to identify the particular factors that shape it, it is necessary to explore such issues through a qualitative approach. Thus, a case-based methodology was chosen [17] and an abductive research process in theory building was conducted [18], [19] (See Figure 1).

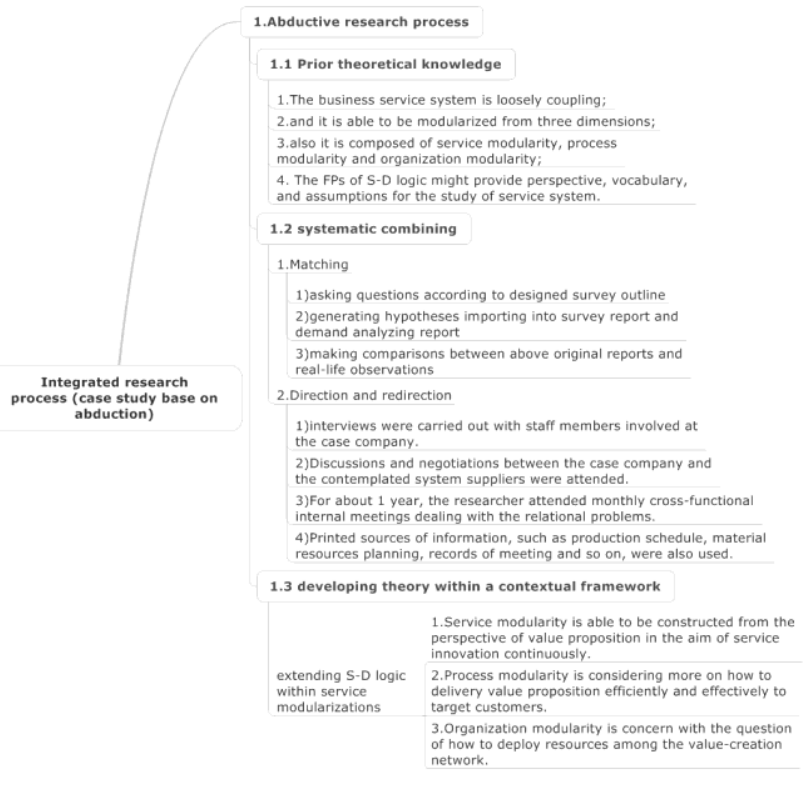

Figure 1. Integrated research process

Firstly, theoretical knowledge like service system, S-D logic or service modularization is already determined prior to empirical observations. Then, by constantly going 'back and forth' from one type of research activity to another and between empirical observations and theory, it is able to expand our understanding on what there are management enablers in modular business service system applying S-D logic. Consequently, a series of creative theory suggestions or 
conclusions (i.e. H/P) are formed as well it can later be tested in a deductive phase of research.

\section{FINDINGS AND DISCUSSIONS}

Along with the fast development of technology, information system like ERP (Enterprise Resource Planning) plays an increasingly important strategic role in business competition. Knowledge and experiences exchange frequently between the service providers and end-users. As participants increase, ERP implementation service as an experience-centric service for consumers has become more and more complex. This research is therefore focused on the service providers and their end-users. The case in this research is defined as a business service system consisting of service software at all levels, corresponding support service processes and all kinds of internal or external resources provided by company A. Both A and its customer (B) are leading companies in their own industries in East China.

\section{A. Findings}

The research results identified three dimensions of modular business service system applying the concept of service modularization: service modularity including service bundles, service modules and service components, process modularity consisted of sub-process modules and activity modules, organization modules composed of internal resources modules and external resources modules. These are mapped in Figure 2. Most important thing is that this modular business service system becomes more and more essential to value creation

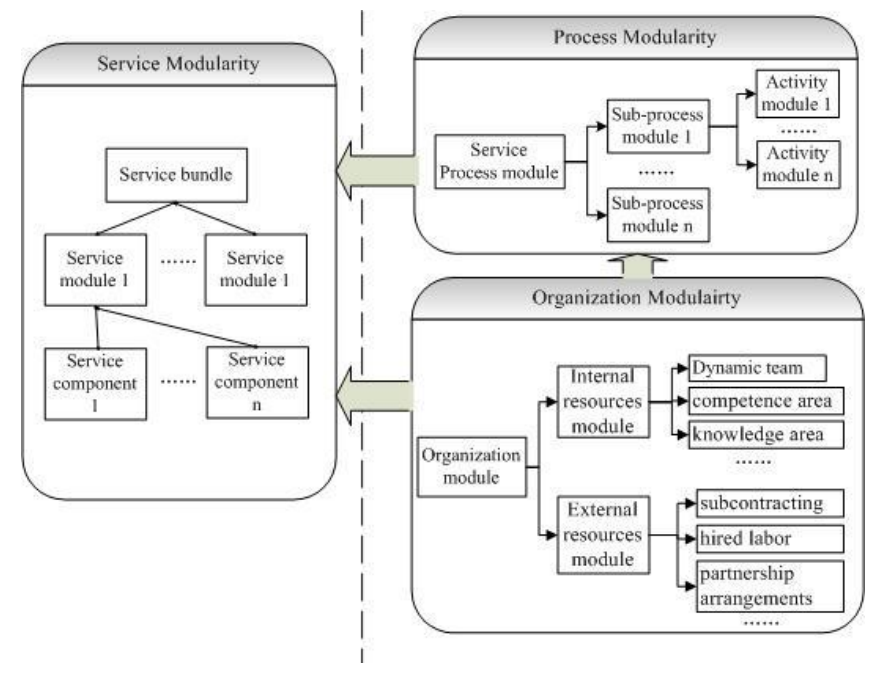

Figure 2. Modular business service system

\section{1) Service modularity}

According to a modular logic adopted by company A, each module could be decomposed into one or more subtle components with specific function and pricing strategy. In order to efficiently and effectively serve for different consumers and various knowledge fields, services provided by company A plays a critical role of its success. Hence, the ERP project in this case is designed with two subsystem, not only product subsystem, but also service subsystem. Whilst, the modular service subsystem is decomposed into service bundles, service modules and service components. Wherein, ERP service subsystem is composed of multiple service bundle such as management consulting service, implementation service and support service and so on; ERP implementation service bundle is consisted of several service modules such as auxiliary implementation service, self-help implementation service, and standard implementation service; Standard implementation service module is composed of many service components such as order management, finance service, logistic management service and so on. Thus, service modularity could be utilized for construction of the "virtual" modular structure (service bundle, service module and service component) based on service concept. Furthermore, this service concept conveys the benefits and value provided to customers [9]. From this perspective, it can be regarded as the company's value proposition [10]. Therefore, in this paper, service modularity is considered as an operative method to enable firms to create service innovation continuously.

\section{2) Process modularity}

The aim of process modularity is to answer the question of how service modularity will be done. For example, Company $\mathrm{A}$ is planning to implement several service components such as finance, logistics, and manufacture management for one special industry-customer. However, implementation service is so complex that it is necessary to ensure the paces of the different process synchronized. Taking standard implementation service module as an example, it is generally including on-site or offsite process modules such as project scope, blueprint design, system building, switch preparation, system switch and continuous support. Each process module, for example, project scope is further decomposed into a quantity of sub-process modules such as internal handing-over, formation of a team, confirming implementation schedule, kick-off meeting and so on. Sequentially, each sub-process module is arranged to a chain of activity modules, for example, internal handing-over sub-process module is composed of four activity modules such as setting a schedule, sales readiness, holding a handover meeting and recording meeting memos. Therefore, from a service procedure view, service component includes a set of processes arranged in a specific order which forms the socalled process module. And each process module performs specific tasks or activities. While, the activity module is described as a combination of activities and teams, and these activities are completed by different teams in the department or sub-company [15]. Consequently, process modularity is focus on the question of how to deliver value proposition to target customers better.

\section{3) Organization modularity}

Due to the integration scope of ERP system designed by Company A has been extended from internal to external resources, the ERP implementation services are not limited in a company view but a supply chain view [20]. Furthermore, this framework of service supply chain is followed the conceptual service supply chain structure proposed by Lin et al., [21] and combined with the various organization modules. Each modular organization of this service supply chain contains standardized ways to organize service provider's internal and 
external resources, so that the processes implemented and services offered are efficient as possible. An internal resource module can include dynamic teams for each customer segment (industry, size, and domain) or for each competence area (solutions provision, solutions distribution, service integration and customer interface) or for each knowledge area (consultant development skill, industry knowledge, domain knowledge, project management knowledge, institutionalized knowledge and so on). An external resource module can include subcontracting, the use of hired labor, and different partnership arrangements with other service providers. Thus, organization modularity is defined as functional units which can be accomplished through various supplier network configurations and internal organizational structures [7]. Therefore, organization modularity addresses the question of "how" to deploy resources among the value-creation network [5].

\section{B. Discussion:The framework of managing modular business service system with the $S-D$ logic}

Enablers to coordinate and manage the three-dimension modular business service system are summarized in Table 2 and Table 3. In the right-hand column, the implications have been analyzed based on the ten FPs of S-D logic in order to understand how S-D logic can help and support the management of the service modularization.

TABLE II. Managing modular business service system with S-D logic

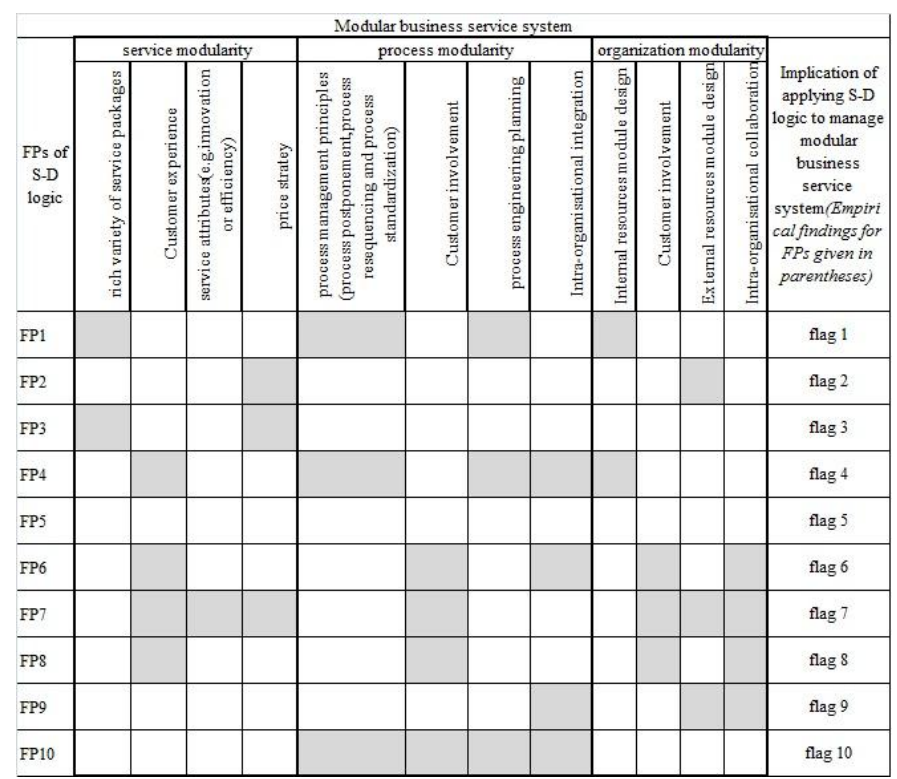

TABLE III. Managing modular business service system with S-D logic (con't) (based on Vargo and Lusch, 2008)

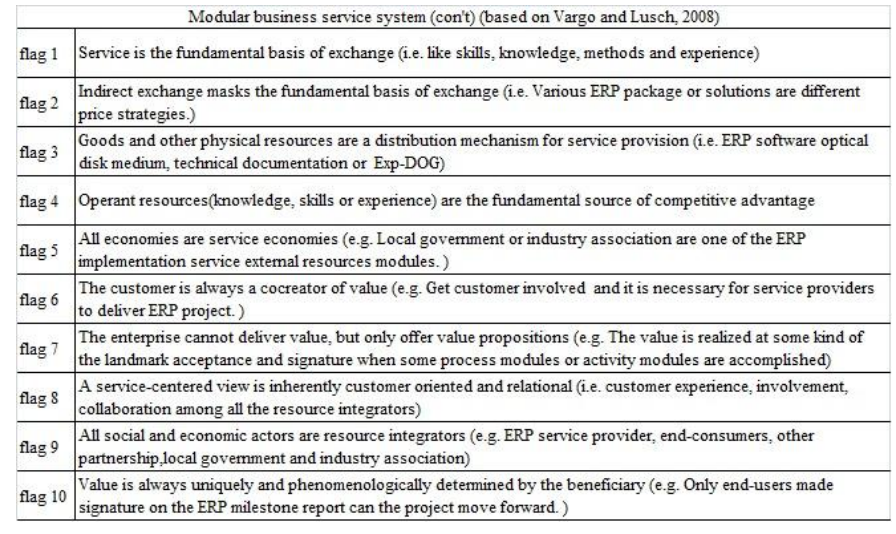

The results show that defining and managing the modular business service system is substantially reliant on the skills, knowledge and experience of the (ERP) service provider, its partnership and customers, which reflects the nature of S-D logic that these operant resources are the primary sources of value and drivers of value creation (FP4). For the ERP service provider in the case study, the experiences and skills accumulated through serving ERP implementation service supply chain [20] are the key to its competitive advantage. With the operant resources such as knowledge area (such as consultant development skill, industry knowledge, domain knowledge, project management knowledge, institutionalized knowledge and so on) in the foregoing organization modularity from the company and its partnership, it ensures the modular business service system can be efficiently managed to create value to the beneficiaries.

Additionally, the consequences also reflect the fact that the focus of economic exchange is shifting from goods to services. It is obvious that the value-in-use of ERP software goes far beyond the value of ERP software optical disk medium. ERP CDs and other hardware goods (for example Exp-DOG) only act as intermediates necessary for delivering service safely and conveniently between the service provider and his consumer, and do not form the basis of the exchange. This is in accordance with the premise of defining goods as a distribution mechanism for service provision (FP3). Traditionally, goods and other operand resources are regarded as the focus in order to ensure the continuity of delivering service and the supply chain, which obviously masks the service-for-service nature of exchange (FP2). It is critical for the consultants, especially for the chief of information officers, to understand and build a service-focused logic to manage modular business service system. This also proves the most basic premise (FP1) of the $S$ $\mathrm{D}$ logic that service is the fundamental basis of exchange, and also follows the premise (FP5) that all economies are service economies.

Another main point emphasized in the results is that the customer plays an indispensible role as value co-creator (FP6) in defining and managing service modularization of business service system. The customer is getting involved each procedure stage of above referred as standard implementation service module. For example, negotiating ERP implementation schedule to collaborate efficiently, analyzing requirements and on-site survey to design matching solutions, holding a system switching conference to distribute solutions better. Obviously, 
the customer is collaborating with the service provider to cocreate value. Furthermore, not only are the ERP software provider and the customer involved in this process, but also local government or relational industry association. The value is actually co-created through collaboration among this valuecreation network [5], they use the resources integrator (FP9) to integrate both operant and operand resources to create value in coordinating and managing the modular business service system.

Following the conception of value-in-use, the ERP service provider did not create and deliver value to the consumer; they only offered value propositions to the customer with the designed solutions (FP7). The value is realized at some kind of the landmark acceptance and signature when some process modules or activity modules are accomplished, which means the value is perceived and measured by the customer (the service beneficiary, FP10). Consequently, defining and managing modular business service system constructed service modularity, process modularity and organization modularity with S-D logic should be customer oriented and relational (FP8).

\section{CONCLUSIONS}

The case study conducted for the purposes of research set out to explore how to apply S-D logic in identifying and managing the modular business service system between the ERP service provider and its customer. This research will contribute to the study of service systems by bridging service modularization with three dimensions (service modularity, process modularity and organization modularity). It is a coincidence to the findings of Pekkarinen and Ulkuniemi [7] by applying integrated approach with a deductive research and an abductive research process. Moreover, this research applies S-D logic into the context of ERP service supply chain, and the result analysis is consistent with the ten FPs proposed by Vargo and Lusch [8].

As this research is limited to the context of high-end software industry, future research could be extended to supply chains in other industries as well to understanding how S-D logic might help the managers in practice.

\section{ACKNOWLEDGMENT}

The authors would like to thank the Guest Editors and two anonymous reviewers for helpful criticism and advice, participants in recent IEEE International Conference on Service Operations and Logistics, and Informatics, where some of the ideas in the paper have been aired and, more specifically, Dr Yong Lin, Professor Shihu Ma and Mr. Feng Yue for helpful advice and contributions at various stages of preparation. The remaining shortcomings are the authors' responsibility.

\section{REFERENCES}

[1] Maglio, P.P., Srinivasan, S., Kreulen, J.T., and Spohrer, J.: Service systems, service scientists, SSME, and innovation, Commun Acm, 2006, 49, (7), pp. 81-85

[2] Maglio, P.P., and Spohrer, J.: Fundamentals of service science, Journal of the Academy of Marketing Science, 2008, 36, (1), pp. 18-20

[3] Neely, A., McFarlane, D., and Visnjic, I.: Complex Service Systems Identifying Drivers Characteristics and Success Factors. Proc. 18th International Annual EurOMA Conference, Exploring Interfaces, Cambridge, UK2011

[4] Vargo, S.L., and Lusch, R.F.: Evolving to a new dominant logic for marketing, Journal of marketing, 2004, 68, (1), pp. 1-17

[5] Vargo, S.L., Lusch, R.F., and Akaka, M.A.: Advancing service science with service-dominant logic, Handbook of service science, 2010, pp. 133-156

[6] Weick, K.E.: Educational organizations as loosely coupled systems, Administrative science quarterly, 1976, pp. 1-19

[7] Pekkarinen, S., and Ulkuniemi, P.: Modularity in developing business services by platform approach, The International Journal of Logistics Management, 2008, 19, (1), pp. 84-103

[8] Vargo, S.L., and Lusch, R.F.: Service-dominant logic: continuing the evolution, Journal of the Academy of marketing Science, 2008, 36, (1), pp. $1-10$

[9] F. Ponsignon, P.A., and Smart, R.S.M.: Service delivery system design: characteristics and contingencies, International Journal of Operations \& Production Management, 2011, 31, (3), pp. 324-349

[10] Skålén, P., Gummerus, J., von Koskull, C., and Magnusson, P.R.: Exploring value propositions and service innovation: a servicedominant logic study, Journal of the Academy of Marketing Science, 2014, pp. 1-22

[11] Lusch, R.F., Vargo, S.L., and Wessels, G.: Toward a conceptual foundation for service science: Contributions from service-dominant logic, Ibm Syst J, 2008, 47, (1), pp. 5-14

[12] Lusch, R.F., Vargo, S.L., and Tanniru, M.: Service, value networks and learning, Journal of the Academy of Marketing Science, 2010, 38 , (1), pp. 19-31

[13] Weick, and Orton: Loosely coupled systems: a reconceptualization., Academy of Management review, 1990, 16, (2), pp. 203-223

[14] Yong, L., and Pekkarinen, S.: QFD-based modular logistics service design, Journal of Business \& Industrial Marketing, 2011, 26, (5), pp. 344-356

[15] Zhou, Z., Lin, Y., Ma, S., and Yue, F.: Modularity of service design for IT company. Proc. Service Operations and Logistics and Informatics (SOLI), 2010 IEEE International Conference on, Qingdao, Shandong2010 pp. 136-141

[16] Shihua, M., Zhou, Z., Lin, Y., and Yue, F.: Modularity Service Platform Design Based on BOM, Industrial Engineering and Management, 2011, (02), pp. 5-11

[17] Voss, C., Tsikriktsis, N., and Frohlich, M.: Case research in operations management, International journal of operations $\backslash \&$ production management, 2002, 22, (2), pp. 195-219

[18] Kovács, G., and Spens, K.M.: Abductive reasoning in logistics research, International Journal of Physical Distribution $1 \&$ Logistics Management, 2005, 35, (2), pp. 132-144

[19] Dubois, A., and Gadde, L.: Systematic combining: an abductive approach to case research, Journal of business research, 2002, 55, (7), pp. $553-560$

[20] Lin, Y., Zhou, Z.K., Zhou, L., and Ma, S.H. (2013), ERP Implementation service supply chain, in Graham, D., Manikas, I. and Folinas, D. (ed.), E-logistics and E-supply chain management: Applications for Evolving business, IGI Global.

[21] Lin, Y., Zhou, L., Rong, K., and Shi, Y.: Service Supply Chain: Configuration Structure and Operations Mechanism, in Editor (Ed.) Service Supply Chain: Configuration Structure and Operations Mechanism (2012,edn.), pp. 336-340 